\title{
MONASHUniversity
}

Australia

Department of Econometrics and Business Statistics

http://www.buseco.monash.edu.au/depts/ebs/pubs/wpapers/

\section{Worker time and cost of stability}

Susan Tregeagle, Elizabeth Cox, Catherine Forbes, Cathy Humphreys and Cas O'Neill

February 2011 


\title{
Worker time and the cost of stability
}

\author{
Susan Tregeagle and Elizabeth Cox
}

Barnardos Australia

\author{
Catherine Forbes* \\ Department of Econometrics and Business Statistics \\ Monash University \\ Cathy Humphreys and Cas O’Neill, \\ Social Work, Melbourne School of Health Sciences, \\ The University of Melbourne
}

February 2011

* Corresponding author: catherine.forbes@monash.edu 


\section{Abstract}

This paper investigates the time caseworkers spend supporting long-term foster care and adoption placements. Undertaken in Australia through collaboration between university and nongovernment agency researchers, the 'Cost of Support Study' tracked the hours that caseworkers spent supporting twenty-seven children and their carers over a nine month period. ${ }^{1}$ The placements were part of a 'Find-A-Family' program for 'hard to place children', many of whom had previously experienced multiple placement breakdowns. The program has a history of 78\% stability on the first placement (over the young person's time in the program) and 93\% by the second, with the type of support provided by this accredited agency's program detailed here. The weekly worker diaries reveal an average of 3 hours 32 minutes of worker time per week per placement; however wide variation is apparent in the time given to each placement, and depends on the characteristics of the child involved. Further, the resources required to support each placement are found by multiplying worker hours by the hourly cost per worker, using New South Wales government costings. The paper contributes to the important debate regarding the link between worker time and stability in care, by deepening our understanding of the costs involved in providing high quality support and supervision of casework.

Key words: stability; longterm foster care; unit costing; permanency; adoption; costs. JEL codes: C19, D63, H75, I38.

\footnotetext{
${ }^{1}$ The research also tracked the time taken by carers for tasks related specifically to the placement - i.e. above and beyond 'ordinary parenting'. See full report of the research at http://www.buseco.monash.edu.au/ebs/pubs/reports/cost-of-support-final-report.pdf; and Research Report Summary (O’Neill, Tregeagle, Forbes, Cox \& Humphreys, 2010). Further papers on the carer findings and the methodology itself are in preparation.
} 


\section{Introduction}

Stability of foster care placements is generally considered an important factor for understanding the poor outcomes that are too common for children and young people who have spent long periods of time in out-of-home care. Breakdowns in foster care or adoptive placements can be traumatic to the children and carers, as well as financially expensive for the community (O’Neill, 1997). While a precise definition of 'stability' is elusive, concern at the damage to children brought about by the instability of placements has been an important area of social work research (Jackson \& Thomas, 1999; Christiansen, Havik \& Anderssen, 2010). While some children need to move placements due to 'policy' concerns such as reuniting with siblings or being placed with kin (James, 2010), unplanned placement moves are described as leading to childhood stress, emotional pain and trauma, decreased attachment and emotional and behavioral disorders, difficulty forming positive relationships, increased foster care cost and carer distress (Pecora 2010). Children themselves complain of the loss of personal belongings, self-esteem and 'personal power', as well as reporting the tendency to 'withdraw' and disconnect from adults (Unrau \& Day, 2010).

Most recent research regarding the factors associated with instability has focused predominantly on the characteristics of the child, the carer household, or the different types of care, such as residential or foster care (Barber \& Delfabbro, 2003; Oosterman, Schuengel, Slot, Bullens \& Doreleijers, 2007; Jones, 2010). Factors such as placing siblings together, worker continuity (Pecora, 2010), worker skills, foster parent assessment and retention (Jones, 2010) are also acknowledged as factors that can assist stability. This paper aims to contribute to the debate on the factors leading to the stability of a placement by exploring the time spent by workers in 
support of the placement. These findings on worker time provide increased understanding of the resources needed by an agency to provide a particular level of stability.

\section{Background}

Over recent years, social work researchers have become increasingly interested in the costs of services (Allphin, Simmons \& Barth, 2001; Selwyn, Frazer \& Quinton, 2006; Selwyn, Sturgess, Quinton \& Baxter, 2006). Particular interest has focused on the comparison of one practice option with another, to understand where funding may be inadequate, and to anticipate the future costs of running a program. Initially undertaken for administrative purposes, this area of research has more recently begun to link data with outcomes such as stability in care (see for example, Beecham \& Sinclair, 2007).

A major difficulty in comparing studies involving stability relates to the different aspects of stability considered. Stability rates are subject to varying degrees of precision owing to the length of time used to estimate the underlying rates; for example, in some studies rates are assessed over a ten year time-frame (Delfabbro, Jeffreys, Rogers, Wilson, \& Borgas, 2009), in others over five years (DHS, 2003). Stability rates themselves are an important outcome measure for long term foster care programs as they gauge a program’s overall ability to establish supported care for children within their foster families. However, to be measured precisely stability rates should be measured over a long period of time, as they are based on information collected regarding the duration of placements. Further, information must be amalgamated over different children, with individual situations having relatively little impact on the overall rate.

In this study, the impact of worker support on individual placements is explored, with stability referring to the absence of placement disruption over the study period. This is particularly 
meaningful in the context of a program with well established stability rates, because the context of stability overall is already established. The aim in this study is to explore detailed information about the amount of time that workers spend on different types of placements and the types of activities that are most important to maintaining those placements within the program. In particular, the variation between different types of children and their placements is of interest, to help understand the way that the program is able to respond to the needs of individual placements over time.

A few studies, in other policy areas, have hinted at the significance of the time workers spend with children and carers, but this has not been the primary focus of research. For example, we know from studies exploring foster carer motivation that interest in maintaining a placement is greatly affected by the adequacy of support and information available from agencies (Brown \& Bednar, 2006). Increasing numbers of foster carers say that they stop fostering because they do not receive the support and positive recognition that they need (Rindfleish, Bean, \& Denby, 1998). Administrative data from the US Child and Family Services Review also identifies stronger stability outcomes related to casework visits to foster parents and children (Sudol, 2010). Also, research directly with foster children has identified that the actions and attitudes of workers affect their experience of foster care. Children and young people report that placements break down when they are not able to get an adequate response from workers, resulting in a lost opportunity to improve the placement (Christiansen et al., 2010). Foster children cite the lack of attention and support they receive from statutory child protection staff and report not being able to trust staff, who, for example, visit infrequently or fail to supply promised transportation (Mathiesen, Jarmon \& Clarke, 2001). 
In the area of costing, there have also been some anecdotal findings about the link between worker time and the stability of a placement. For example, adoption rates are higher in programs with greater staffing and resources (UK Department of Health, 1999). Improved short-term stability for children in care is noted following increases in government funding in the United Kingdom (UK) subsequent to changes in legislation (Jackson \& Thomas, 1999, p.31). The 'number of case managers allocated to clients' is noted as an important indicator of stability in Australian foster care (DHS, 2003 p.64), and a lack of contact between children and workers is seen as a significant factor in placement instability (Gilbertson \& Barber, 2004). However, more direct research into worker time and agency resources is needed.

Costing studies have generally taken one of two approaches to calculate the cost of services (Beecham, 2004). The first, a ‘top-down’ approach, divides the total budget by service output. In contrast, a ‘bottom-up’ approach analyses actual costs and processes associated with individual placements or service areas (Beecham, 2004; Selwyn et al., 2006). Top-down approaches have been used in Australia (SCRGSP, 2010) and the UK to calculate the cost of care and adoption (Selwyn \& Sempik, 2010). However, top-down costing is poor at establishing comparative costs. The bottom-up approach has been used in the UK to anticipate the cost of placements before they commence (Ward \& Holmes, 2008). However, in practice bottom-up studies typically draw their data from focus groups well after the work has taken place, and therefore the accuracy of such data is suspect since it relies on the somewhat distant memories of the participants, an approach known to be fraught with errors (Conrath, Higgins \& McLean, 1983). One recent exception is the work of Holmes, Westlake \& Ward (2008) which used 'event records' (workers completing time diaries) for 15 children to arrive at cost estimates of particular placement processes. The authors 
note, however, that only four workers completed three months of data recording and that the average completion length was far shorter at 26 days.

This paper contributes to the important, but inchoate debate on the link between worker time and stability in care using a robust bottom-up methodology, where workers regularly record the actual time and type of activity undertaken to support a placement. We present a detailed analysis of worker time and costs associated with the delivery of a long term foster care program which has an accredited level of quality and established high rate of placement stability. In addition, the amount of support provided to placements is explored across various placement characteristics, including the age of the child, the intention to proceed to adoption and the time in care.

\section{The cost of support study}

\subsection{The study site}

In Australia, out of home care (OOHC) is the responsibility of state governments and each state therefore has its own range of relevant legislation and policies. There is also a strong nongovernment sector which provides much of the actual OOHC work, funded mainly by the relevant state government. This paper describes a research project which took place in the state of New South Wales, Australia, over nine months within 2008-09 and within the context of a non-government agency that has operated for over twenty-five years. Conducted within the Barnardos Australia Find-A-Family (FAF) program, a specialist permanency program that takes children separated from their families by the court until the age of 18 years, the study was undertaken to look at the cost of providing support to, and therefore facilitating stability in, longterm foster care and adoptive placements. In the FAF program, children either stay in long-term 
foster care or may be adopted, with the agency having full case-management responsibility (that is workers do not share decision-making with the statutory workers during the placement). The program specializes in 'hard to place' children and was the first program to receive government accreditation in Australia. The program is independently audited each year by the New South Wales Office of the Children's Guardian (www.kidsguardian.nsw.gov.au) in relation to policy, education and health assessment, record keeping, assessment, training of workers and carers, supervision and governance. All workers use the internationally recognized Looking After Children (LAC) case management system, developed in the UK in 1990s and adapted for Australia in 1997 by the LACPROJECT Australia (Cheers \& Morwitzer, 2008) to establish agreed levels of regular assessment in a range of areas (e.g. health, education, relationships) and to facilitate the ongoing review of each child's progress. Further information is available regarding the long term outcomes for children in the FAF program (Fernandez, 2006; Fernandez, 2008; Fernandez, 2009).

A general description of the program is provided here to allow greater understanding of the costed model of care. FAF is based on the Barnardos UK family finder program, and provides care for children who have either experienced multiple disruptions in foster care, or are babies or toddlers with complex family backgrounds who have no possibility of returning to their birth parents' care. FAF specializes in placing large sibling groups and children who require culturally specific placements as these are children who frequently have the greatest difficulty being placed. Based on the NSW government's criteria for additional placement funding ${ }^{2}$, over two thirds of the children have behavior described as either very difficult (30\%), or extremely or extraordinarily difficult (38\%).

\footnotetext{
${ }^{2}$ There are four categories of NSW government funding, ranging from Care (ordinarily difficult), Care+1 (very difficult), Care+2 (extremely difficult) to Care+2+ (extraordinarily difficult).
} 
Adoption is the care plan for up to half of the children in the program and the average age at legal finalisation of the adoption is 10 years. In keeping with the Secretariat National Aboriginal and Islander Child Care guidance (SNAICC, 2008) and Aboriginal cultural views on adoption, FAF would not normally accept an Aboriginal child into care, and adoption would only be considered in consultation with Aboriginal communities and elders.

The FAF program operates under the New South Wales Children (Care and Protection) Act 1997, and each child has finalized Children's Court Orders committing them to care until age 18. Parents have rights to seek revisions of these Orders. However, under separate adoption legislation, children can also consent to their own adoption after the age of 12 years.

The FAF program has a history of 78\% stability on the first placement (over the young person's time in the program) and $93 \%$ by the second; see Figure 1. Given the special needs and challenging nature of the children, the FAF stability rates appear to be high. These rates were calculated using over twenty-three years of records, and relate to the entire period of involvement for all children in the program (children remain with the program until adoption or 'aging out' of the program).

Although difficult to provide direct comparisons, as few studies focus on stability for the subgroups of very damaged children who have been in the care system for a long time, it is clear that the FAF figures are impressive. However, US data shows an average of 3.2 placements per child with a median length of stay of 15.3 months in a Californian study of the general foster care population, showing that $77 \%$ of children had three or more placements (Pecora, 2010). An Australian study demonstrated that almost $80 \%$ of a particular comparison group had experienced seven or more previous placements (Delfabbro et al., 2009). In another Australian 
study conducted over a five-year period of the general foster care population, children and young people experienced an average of 3.4 foster placement changes, and $23 \%$ had five or more placements (DHS, 2003, p.59).

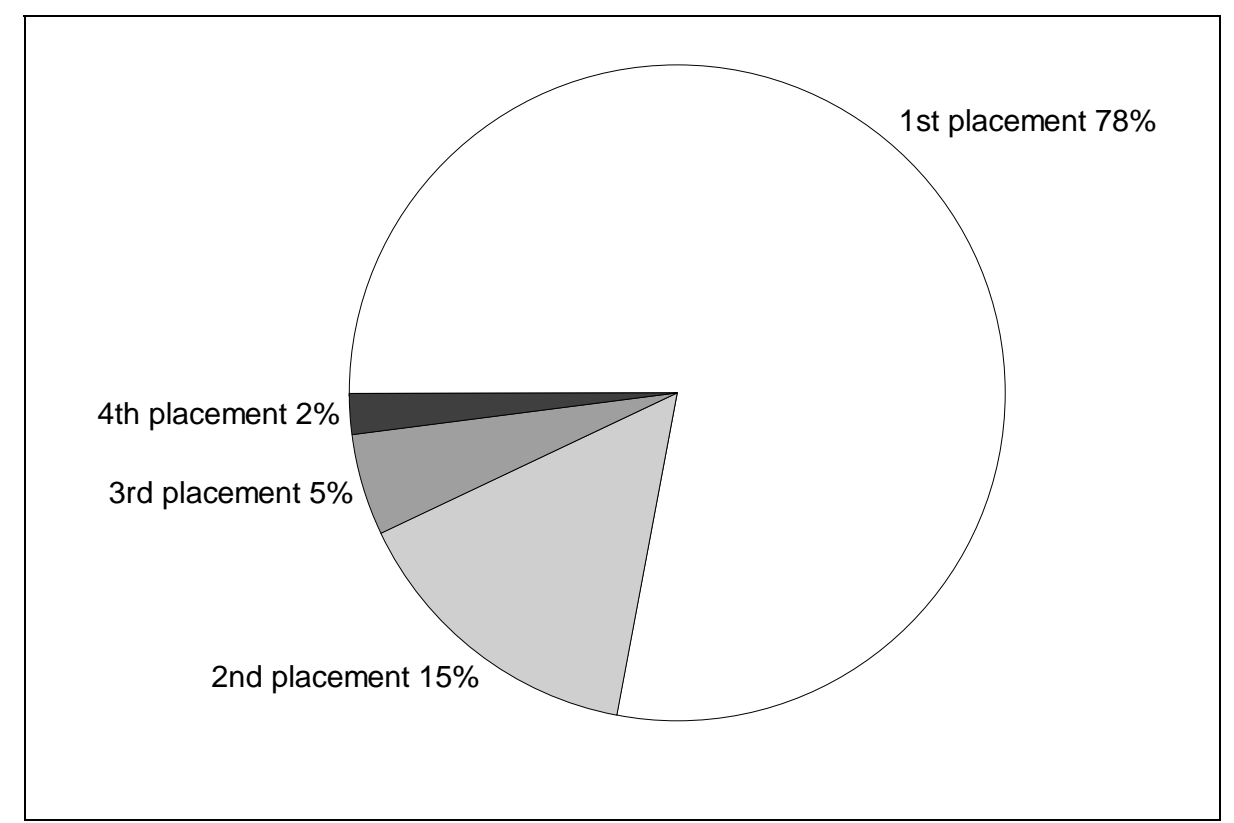

Figure 1: Stability rates for placements in Barnardos FAF Program, October 1984-February 2008 $(\mathrm{N}=365)$. This is the rate at which children found a permanent family, or who exited the program to adoption or independent living, in their first or subsequent permanent placements.

FAF has well established principles of practice, based on the available research literature regarding children's attachment and poor outcomes in traditional out of home care. On entry into the program, children and young people generally enter a 'bridging placement' for 12-18 months (not counted in this study as a permanent placement), until child specific recruitment efforts result in an appropriate family being found. Due to their critical attachment needs, children under the age of three are usually placed directly with an adoptive family and are not associated with such individualized recruitment procedures. Note that for these young children, an adoptive family is often much easier to recruit. The child's introduction to the placement usually takes 
place gradually, over a number of visits, and unrelated foster children are rarely put together in one placement (Ingley \& Earley, 2008).

Case workers have daily to weekly contact with children at the beginning of placement in order to establish the arrangement. Support remains in place on an ongoing and 'as-needed' basis. Active age-appropriate participation by the child or young person in decision making is strongly encouraged and birth family engagement with the children is generally ongoing, including after an adoption. Workers monitor placements regularly and support is offered to carers to avoid small issues threatening the placement. Carers have access to their twenty-four hour 'on call' phone numbers. Supervision and ongoing training are provided for carers as soon as a child is placed, alongside other practical support structures (counseling, education, health) which help to resource long term placements, particularly those for children and young people with very difficult behaviors. This support, supervision and ongoing training are seen as necessary for the maintenance of a high quality service, both to children and their carers.

\subsection{Study Method}

This article reports on the findings from research based on diary records maintained by workers relating to the support provided for twenty-seven children in the FAF program from November 2008 to August 2009. A blank copy of the diary page used for data collection is included in the Appendix. The research was funded by a philanthropic organisation (The Ian Potter Foundation) and ethical clearance was gained through the University of Melbourne Human Ethics Committee and confirmed by the Monash University Human Research Ethics Committee. 
At the outset of the study, twenty-five placements were selected through a purposeful sampling design, where five placements from each of five different groups were selected, representing a broad range of placement characteristics. The five pre-determined study groups were:

- $\quad$ Adolescent group: young people thought to be vulnerable to instability due to being in adolescence, aged between 12 and 16 years;

- $\quad$ First Year group: children and young people in their first year of placement;

- Unstable group: placements where staff members were concerned about the stability of the placement at the commencement of the project;

- $\quad$ Stable group: placements considered to be in a 'stable/average' category, viewed as a control group;

- $\quad$ Adoptive group: pre-adoptive placements, where the placement was intended to proceed to adoption, and although thought to be stable, could potentially require greater levels of worker time because of the care plan.

The five individual placements selected within each group were chosen at random, subject to ensuring that workers were not unduly burdened with multiple placements and also where carers were willing to participate.

In addition to the original sample of twenty-five placements, placements for two further children were added partway through the study when it was apparent the placements were stressed and therefore vulnerable to disruption. It was felt that it was important to get data on potential disruptions to compare with previous studies in the area (O'Neill 1997). These two placements are referred to as the Imminent Risk group. 
Each week for nine months, the workers recorded the hours of work completed each day (in 15 minute blocks), indicating the category of activity undertaken, for each placement in the study. Consistent administrative follow up was provided, resulting in only $2.3 \%$ of days where data was not recorded. Managers were also asked to detail, on a weekly basis, any time spent on placements involved in the study as, in addition to routine supervision, they provide additional support when difficulties arise within a placement or when a worker is away on leave. Manager time is therefore treated as a separate category within the worker data.

The subsequent costing of time was undertaken using the NSW Government costing data, which importantly includes all overheads and non-client related time.

\subsection{Worker costs}

Costs calculated from the study represent the cost of the hours provided by workers and are based on an hourly rate provided by the FAF funding body (NSW Department of Community Services) for the 2008/9 year. The cost of each Full Time Equivalent (FTE) notional worker position has been determined by the funding body at $\$ 163,480$ per annum. ${ }^{3}$ This figure does not include carer payments or contingency payments which cover such costs as additional education, health and recreational activities. The calculation is reproduced in Table 1 for completeness, and to allow adaptation of the formula to other times or local conditions.

The hourly rate associated with Table 1 is calculated for a 38 hour week, with 207 days available for work (365 days excluding weekends, public holidays, recreation and sick leave and training),

\footnotetext{
${ }^{3}$ All dollars quoted are Australian dollars. On 4 November 2010 the US and Australian dollar were virtually equivalent. (Reserve Bank of Australia, http://www.rba.gov.au/statistics/hist-exchange-rates/index.html, downloaded 5 November 2010.)
} 
resulting in 1,626 hours available per worker, per year. Included in the activities are non-client related work such as general team meetings, supervision and administration.

Barnardos Australia managers reported that they view this formula as a good approximation of the FAF program costs. When considering the costing formula, it should be noted that the workers in this study did not undertake recruitment of foster carers (this is done by specialist officers), however this is included in the hourly rate. Also, Barnardos workers have full legal responsibility for the children and are not involved in liaison with statutory workers or involved in court preparation. They also only work 140 hours over a four week period, with time off in lieu enforced for any time spent with work at night or weekends. All workers hold a four year undergraduate degree in social work or psychology, while some also hold a Master's degree in these areas.

\subsection{Calculation of the average hours per day}

A key objective of the research was to calculate the cost of support for a worker per week (or correspondingly, per day), and hence we investigated the average number of hours per day for each placement over the study period. As well as direct client contact, the hours included phone calls, letters, supervision, meetings and travel time - i.e. anything related to the child or placement. The total hours recorded on the diary sheets relating to an individual child or young person was divided by the total number of working days available. ${ }^{4}$ A large proportion of workers are employed part-time, with varying flexible working arrangements in place. However, as the amount of work for each worker is managed by the total number of cases in a worker's caseload, the number of available days during the study was not adjusted to reflect the nominal

\footnotetext{
${ }^{4}$ Public holidays and days of annual leave were excluded.
} 
employment fraction of the worker. It would be expected, therefore, that the average number of hours per actual working day would be higher on average for a part-time worker than for a fulltime worker, if all other factors were the same, simply because the same level of support is expected in fewer days per week. Hence, we interpreted the average number of hours per day as being representative of a nominally full time worker.

\begin{tabular}{|c|c|c|c|}
\hline $\begin{array}{l}\text { Caseworkers - Indicative Unit Cost per } \\
\text { FTE }\end{array}$ & Low Range & High Range & $\begin{array}{l}\text { Indicative } \\
\text { Cost }\end{array}$ \\
\hline \multicolumn{4}{|l|}{ Unit Labour Costs (per FTE) } \\
\hline Caseworker Base Salary & $\$ 47,900$ & $\$ 58,540$ & $\$ 53,220$ \\
\hline Direct Supervisor Allocation & $\$ 10,390$ & $\$ 12,690$ & $\$ 11,540$ \\
\hline Admin and Other Indirect Support Allocation & $\$ 18,670$ & $\$ 22,810$ & $\$ 20,740$ \\
\hline Salary Oncosts & $\$ 13,370$ & $\$ 16,340$ & $\$ 14,851$ \\
\hline A. Total Unit Labour costs & $\$ 90,330$ & $\$ 110,380$ & $\$ 100,350$ \\
\hline \multicolumn{4}{|l|}{ Unit Non-Labour Costs (per FTE) } \\
\hline Motor Vehicle & & & $\$ 13,240$ \\
\hline IT/Computer & & & $\$ 4,920$ \\
\hline Telecommunications & & & $\$ 1,310$ \\
\hline Stationery/postage/printing & & & $\$ 1,610$ \\
\hline Depreciation and Equipment Maint. & & & $\$ 1,960$ \\
\hline Staff Training & & & $\$ 3,630$ \\
\hline Accommodation & & & $\$ 10,360$ \\
\hline Corporate Overheads \& Other & & & $\$ 26,100$ \\
\hline B. Total Unit Non-Labour Costs & $\$ 56,820$ & $\$ 69,440$ & $\$ 63,130$ \\
\hline Total Loaded Cost per FTE (A+B) & $\$ 147,150$ & $\$ 179,820$ & $\$ 163,480$ \\
\hline Labour Cost Factor & & & $61 \%$ \\
\hline Non-Labour Cost Factor & & & $39 \%$ \\
\hline Total Available Hours & & & 1,626 \\
\hline$\%$ of time - non client related & & & $20 \%$ \\
\hline Service Hours Available & & & 1,301 \\
\hline Cost Per Direct Client Hour & $\$ 113.1$ & $\$ 138.2$ & $\$ 125.6$ \\
\hline
\end{tabular}

Table 1: Cost of FTE Notional Caseworkers In Out Of Home Care in Australian dollars, from Costing Manual for Child and Family Services in New South Wales 2008-9 'Out of Home Care Services', Department of Community Services (www.community.nsw.gov.au, accessed 1/4/2009). Note that nonclient related data is included in this costing. 


\subsection{Characteristics of the children and young people in the study}

The twenty-seven children and young people who participated in the study comprise about 15\% of all children in the FAF program. Twelve male and fifteen female children and young people were associated with the study, with six children aged less than 5 years, five aged 5-9 years, eight aged 10-14 years and eight aged at least 15 years at the start of the study. These characteristics represent a relatively even spread of gender and age across the population of children in the program.

Participants were identified ${ }^{6}$ as having special needs according to the four categories used by the NSW funding body:

- $\quad$ Ten rated within the 'Care' category, with behavior defined as 'ordinarily' difficult for foster care;

- $\quad$ Eight rated as 'Care +1 ', with behavior classed as 'very difficult';

- $\quad$ Six rated in 'Care +2 ' having 'extremely difficult' behavior; and

- $\quad$ Three rated as 'Care +2+', with 'extraordinarily difficult' behavior.

Seventeen children in the study were therefore designated as having special behavioral or medical needs, with up to six identified health issues (average 1.7) at the time of entry into the FAF program. The most common problems were Attention Deficit Hyperactivity Disorder (ADHD) and mental health problems. Twelve children required extra assistance with their education, nine were reported to be performing at or above average educationally and six were in childcare or pre-school with no reported developmental delays.

\footnotetext{
${ }^{6}$ Identification of special needs and payment categories is a negotiated process between the placement agency and the NSW Department of Community Services prior to the agency accepting the child for placement.
} 
The children and young people had been in care (with Barnardos or previously with another agency, as of 1 January 2009) for an average of 6.2 years, including the current placement. Prior to the current placement, together the children had been in 105 placements with an average of 3.8 placements each and with a range of one to eight placements each. Nine had a care plan of longterm care with adoption, one was moving to independence and the remaining care plans were for long-term foster care (this proportion is also broadly representative of the program as a whole).

The most usual contact arrangement with birth families in the FAF program is four contact visits each year, however contact arrangements vary widely, with two children in the study having no contact with any family member and one having twelve visits per year. In addition to contact with the birth mother, visits with fathers, extended family and previous carers are also facilitated. Fourteen of the participants in the study had active contact with siblings. Twenty-four children/young people had siblings in alternative placement situations, including some other foster care placements or with birth family members. Eight of the children were placed with their siblings, but five of these also had other siblings living elsewhere.

\subsection{Limitations of the study method}

Like all research studies there are limitations as well as strengths in the methodology that has been used. A number of issues need to be taken into account:

a) The study sample is small. In taking five cases from each category there may be children in the sample who are atypical in each of the categories.

b) There was some variability in the compliance with diary entry by workers. Regular follow up and feedback by researchers and managers supported a high level of 
compliance, but of course this does not ensure 'perfection', with $2.3 \%$ of diary days missing.

c) The choice of participants was initially randomly chosen from the designated categories, but subsequently on which dyads of workers and carers were most likely to keep diaries accurately. It is therefore possible that the most conscientious carers were included in the study.

d) There may have been a 'research effect', as there were no disruptions in the nine month period for this group of children and young people. However, we note that there were some 'threatened' disruptions, as well as two disruptions (from the study group) within a few months following the end of the study period.

Despite these limitations, we believe that the study data retains a high degree of accuracy and leads us to have confidence in the resulting findings.

\section{Results}

The findings of the study are presented in terms of worker average hours, by study group, by activity, and according to a selection of placement characteristics. Worker costs are also included, by study group and placement characteristics.

\subsection{Worker average hours per day per placement}

A total of 3282.85 hours of work, including hours recorded outside of normal working periods, was recorded by the workers. These hours were collected from the 4,637 working days associated with the twenty-seven cases over the entire research period, resulting in an average of 0.71 hours, or about 42 minutes of worker time, per day per placement in the study. Due to the 
stratified sampling design, a simple average across cases need not represent the overall worker average time for the Barnardos FAF program. However comparing the care difficulty rating proportions in the sample against those in the overall Barnardos FAF program in 2008, this average figure may be considered as representative of the overall worker average time per day for all placements in the FAF program.

Across the twenty-seven placements, workers spent on average 3 hours 32 minutes per child per five day week during the study. However, the average time hides the large differences in individual worker average time per placement, which were found to range from 16 minutes per day to 79 minutes per day. These individual times also varied according to the category of placement.

\subsection{Worker time by group}

Worker average time for each study group was obtained by totaling the hours for all workers within the relevant group, and then dividing by the number of cases within the same group. From Table 2 it is evident that the Imminent Risk, First Year and Unstable groups were associated with the highest levels of worker time. In particular, the worker average per day time for the First Year group was more than twice the average time from any of the Adolescent, Adoptive or Stable groups.

\begin{tabular}{lccccccc}
\hline Group & $\begin{array}{c}\text { Imminent } \\
\text { Risk }\end{array}$ & $\begin{array}{l}\text { First } \\
\text { Year }\end{array}$ & Unstable & Adolescent & Adoptive & Stable & All \\
\hline $\begin{array}{l}\text { Average hours per } \\
\text { study day }\end{array}$ & 1.32 & 1.01 & 0.91 & 0.49 & 0.47 & 0.46 & 0.71 \\
$\begin{array}{l}\text { Number of cases in } \\
\text { Group }\end{array}$ & 2 & 5 & 5 & 5 & 5 & 5 & 27 \\
\hline
\end{tabular}

Table 2: Summary of worker average hours, per placement, per day, for each study group, and over all placements in the study. 
The above is not meant to suggest that the remaining three groups (Adolescent, Adoptive and Stable groups) did not require significant support, with each requiring an average of just under a half an hour per day. The worker average time was slightly higher in the Adolescent group than for either the Adoptive group or Stable group, and in all cases the average number of hours per worker per day can vary considerably even within the same study group.

In addition to the differences in average levels of support both between and within groups, every individual case required a variable amount of support over time. On many days the worker time was much greater than the daily average would suggest, and correspondingly there were also days when time spent was negligible. Figure 2 displays the daily hours recorded for one particular placement, associated with the Imminent Risk group, over the days recorded during the study. The ebb and flow of worker support shown is indicative of that found in all placements in the study, despite the differences in the overall level of support required for each.

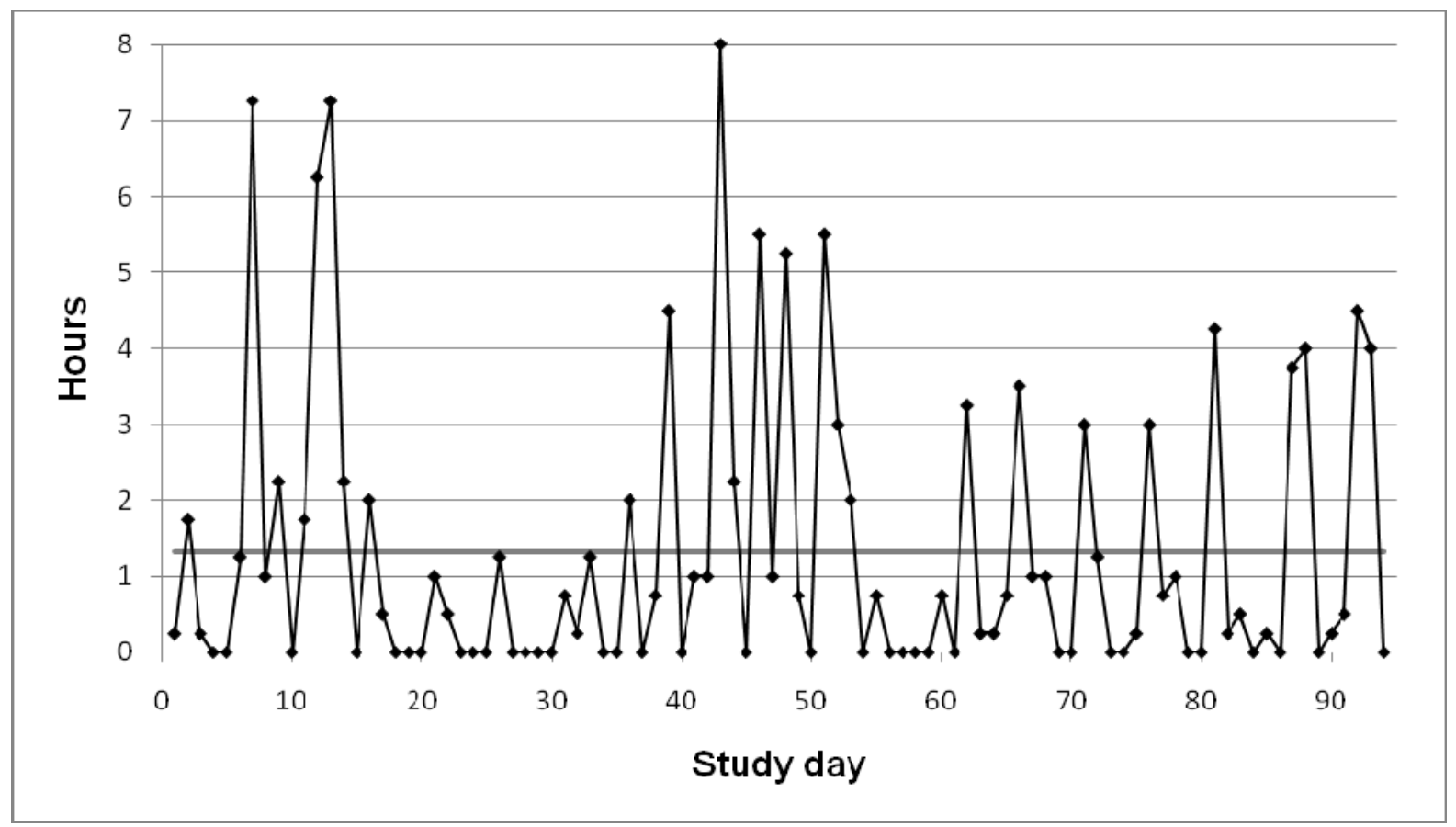


Figure 2: Worker hours per study day for a placement. This figure shows an example of variability in hours of worker support over consecutive study days for case \#1 in Imminent Risk group. The total recorded hours of worker support provided for this case over the study period is indicated by the sequence of connected dots. The corresponding average hours per study day associated with the case is 1.32 hours is indicated by the solid line. Note that 'study days' includes all days when records were recorded for placement, and does not include weekends or public holidays.

The average number of years that the children in the study were placed in any care program does vary somewhat per group, and this may have some impact on the overall findings. However, the pattern is not entirely obvious, with the First Year group having the shortest period in care (as of 1 January 2008) and the Unstable group having the longest period in care, on average. The two cases at Imminent Risk of disruption during the study had periods of care in any program less than the overall average of 6.3 years for all children in the study. This is coupled with the fact that the least demanding placements, apart from those in the Unstable group, tend to be associated with children who have been in care for slightly longer periods. A similar result -

\begin{tabular}{lccccccc}
\hline Group & $\begin{array}{c}\text { Imminent } \\
\text { Risk }\end{array}$ & $\begin{array}{c}\text { First } \\
\text { Year }\end{array}$ & Unstable & Adolescent & Adoptive & Stable & All \\
\hline Time in any program & 5.0 & 3.1 & 9.0 & 7.6 & 5.5 & 6.6 & 6.3 \\
Time in FAF & 3.5 & 1.0 & 7.7 & 7.5 & 4.2 & 5.4 & 5.0 \\
\hline
\end{tabular}

Table 3: Average number of years of care in any foster care program (row 2), and average number of years in specific FAF program (row 3), for children in each study group and overall.

\subsection{Worker time by activity}

Over $80 \%$ of the total hours recorded ${ }^{7}$ may be attributed to the following eight main worker activities:

\footnotetext{
${ }^{7}$ These eight categories of activity represent $83.7 \%$ of all hours reported for all placements over the study period.
} 
- $\quad$ Contact with foster carers/adoptive parents (18.9\%)

- $\quad$ Administration - case notes, reports, etc (16.3\%)

- $\quad$ Contact with child/ren only (13.0\%)

- $\quad$ Contact with carers/children together (10.2\%)

- $\quad$ Manager hours (9.4\%)

- $\quad$ Work with birth family (6.7\%)

- $\quad$ Access arrangements and supervision - birth parents (4.7\%)

- $\quad$ Adoption related work (4.4\%)

The percentages indicated above are found by taking the total hours associated with the relevant activity for all workers in the study over all days, and dividing that by the total number of hours reported by all workers on all days, on any activity. Other categories that required less than $4 \%$ each of the overall worker time included supervision, access with birth siblings or other family members, educational issues, health or counseling issues, internal meetings or meetings with other agencies.

However, the relative percentage of time required by workers for various activities was not constant for each study group. Table 4 details the percentage of time workers within each group spent on each of the same eight activities. The first column details the categories of activity investigated. The second column gives, in descending order, the overall percentage of time over the study period for the activity listed in the first column. In the subsequent columns, the percentage of time that workers within the group (indicated by the column heading) spent on the nominated activity, relative to all of the time recorded for that group, is given. This layout enables the reader to identify the top eight activities in terms of worker time overall, as well as how demanding that particular activity is relative to the individual study groups. For example, 
while time with carers or adoptive parents is of relative importance for all groups, as it ranks as requiring the highest overall time across the study and accounts for at least $15 \%$ of time in all groups, this activity is only associated with the highest proportion of time recorded for the First Year, Unstable and Adolescent groups. Similarly, while time spent on adoption related matters ranks as only the eighth most time consuming activity overall, it is understandably the most time consuming activity for the Adoptive group, and is a relatively important activity for the Stable group.

\begin{tabular}{lccccccc}
\hline Worker activity & All & $\begin{array}{c}\text { Imminent } \\
\text { Risk }\end{array}$ & $\begin{array}{c}\text { First } \\
\text { Year }\end{array}$ & Unstable & Adolescent & Stable & Adoptive \\
\hline $\begin{array}{l}\text { Carers/ Adoptive } \\
\text { parents }\end{array}$ & $18.9 \%$ & $17.8 \%$ & $15.2 \%$ & $21.5 \%$ & $24.1 \%$ & $17.3 \%$ & $14.7 \%$ \\
Administration & $16.3 \%$ & $13.8 \%$ & $14.2 \%$ & $18.2 \%$ & $15.1 \%$ & $17.9 \%$ & $15.3 \%$ \\
Children only & $13.0 \%$ & $25.8 \%$ & $9.5 \%$ & $17.4 \%$ & $17.1 \%$ & $6.3 \%$ & $1.0 \%$ \\
Carers/ Children & & & & & & & \\
together & $10.2 \%$ & $8.5 \%$ & $13.0 \%$ & $7.6 \%$ & $10.1 \%$ & $10.1 \%$ & $9.3 \%$ \\
Manager & $9.4 \%$ & $14.8 \%$ & $13.4 \%$ & $6.5 \%$ & $11.4 \%$ & $15.4 \%$ & $10.0 \%$ \\
Birth family & $6.7 \%$ & $3.7 \%$ & $6.3 \%$ & $4.1 \%$ & $4.9 \%$ & $8.9 \%$ & $13.5 \%$ \\
Access - birth parents & $4.7 \%$ & $0.0 \%$ & $6.3 \%$ & $4.5 \%$ & $3.9 \%$ & $3.7 \%$ & $7.0 \%$ \\
Adoption related & $4.4 \%$ & $0.0 \%$ & $2.1 \%$ & $0.7 \%$ & $1.3 \%$ & $10.4 \%$ & $17.3 \%$ \\
\hline Total top 8 for group & $\mathbf{8 3 . 6 \%}$ & $\mathbf{8 4 . 4 \%}$ & $\mathbf{7 9 . 8 \%}$ & $\mathbf{8 0 . 4 \%}$ & $\mathbf{8 7 . 9 \%}$ & $\mathbf{9 0 . 1 \%}$ & $\mathbf{8 8 . 1 \%}$ \\
\hline
\end{tabular}

Table 4: Top eight worker activities, overall and by group. Group percentage times for overall top eight activities ranked according to the percentage of time on activity relative to the total hours recorded during the study across all participants within the group. The 'Total top 8 for group' shown in the bottom row of the table denotes the total percentage of the relevant group's time spent on these eight categories only.

Other specific findings relating to the relative importance of various activities by group include:

- The top four activities accounted for nearly $60 \%$ of worker time. Notably, three of these four activities deal directly with the children or their carers. 
- $\quad$ The top five activities overall accounted for over $80 \%$ of the Imminent Risk group worker time. In addition, no time was spent by this group on either access with any relationship, adoption related work, or meetings with other agencies over the period of the study.

- The findings of both the Unstable and Adolescent groups were quite similar to the First Year group, albeit with relatively more time spent with children by themselves. For both of these groups, adoption related work dropped to a very small percentage of each group’s overall time.

- Six of the top eight activities accounted for over $80 \%$ of the Stable group’s time. A similar result was found for the Adoptive group.

It is apparent that workers do shift activity priorities according to the needs of individual placements. It seems that a great deal of time is spent on cases within their first year, with an emphasis on working with the children and their carers. Significant time is also spent on the birth family in terms of support by the worker and access to the children. Then, when placements are more stable, relatively more time is spent on adoption-related work.

\subsection{Worker time and placement characteristics}

In this section, the relationship between worker average hours per day and gender, age, health, and other placement characteristics known at the start of the study is explored. No claims are made regarding cause and effect of worker time and the characteristics of the children, and the research process considered factors only one at a time. With the relatively small number of cases and other limitations of the study, the possibilities to explore interactions of this type are limited, 
and do not provide adequate scope to determine statistical significance. They nevertheless point to some trends in the data.

- Cases involving male children were slightly more demanding of worker time, with an average of 45 minutes per day, compared with an average of 38 minutes per day for workers relating to cases involving female children.

- The average time per day spent by workers was the lowest (an average of 33 minutes per day) for cases involving children in care under the age of 2 years, and the highest (49 minutes per day) for cases involving children in the 3-5 year age group. As the children get older, worker time per case declines, on average, with children aged 6 to 11 years of age associated with 45 minutes of worker time per day and children aged 12 years or older in the study associated with 40 minutes per day.

- There is not an obvious pattern between worker demand and the number of health issues identified at the start of a placement; however worker time is higher, on average, for cases associated with more difficult care categories. Placements with children in the 'Care' and 'Care +1 ' categories were associated with an average of 37 and 38 minutes of worker time per day, respectively, whereas placements with children in the 'Care +2 ' category were associated with 49 minutes per day, and placements with children in the 'Care +2+' category were associated with 56 minutes of worker time per day.

- The demand for worker time is lower for placements with a long term foster care plan leading to adoption, than for placements with a long term foster care plan without adoption. Worker time on placements with long term foster care leading to adoption averaged only 34 minutes per day, whereas worker time with long term foster care placements not associated with adoption averaged 47 minutes per day during the study. 
- Worker time appears to decline the longer the child has been in any care program. If a child was within the first two years of care, the placement required an average of 53 minutes per day from the worker, whereas if the child had been in care more than two years, but less than five years, the placement required an average of 43 minutes. Placements where the child had been in care more than five years averaged only 38 minutes per day from the worker.

- Considerable worker time is spent during the first year of the FAF program to establish the placement as well as to attend to a wide range of medical and social issues, resulting in an average of 64 minutes per day. We believe that the benefit of intensive work within the first year is that the overall level of time spent in subsequent years is reduced, with only 30 minutes spent on average over the second, third and fourth year in the program. However some years later support levels do gradually appear to increase, with 36 minutes the average worker time per day spent on placements where the child has been in the program for between five and eight years, and 41 minutes per day averaged by workers for placements having been stable in the program for nine years or more. We speculate that this finding may be representative of either more complex long term placements that do not result in adoption and/or could be due to the young people preparing to leave care.

- Worker time is marginally lower, at 39 minutes per day on average, for placements without respite support, than for placements with respite support, averaging 43 minutes per day. This may reflect the tendency for placements with a more difficult care category to receive respite support.

- The range of worker experience levels (based on years of experience within Barnardos, together with salary levels) for those in the study was mixed, with ten novice workers, nine 
more experienced workers and seven senior workers. ${ }^{8}$ However, all workers completed the same case management system documentation (LAC) and each had the same level of supervision (monthly one-two hours with their immediate supervisor). Average time per placement per day for the novice workers was 45 minutes, more experienced workers spent 47 minutes, and senior workers spent 35 minutes.

\subsection{The cost of worker time}

Having obtained the average daily levels of worker time associated with each of the twentyseven cases in the study, the average daily costs were obtained. These were calculated by multiplying the average number of worker hours per day by $\$ 125.60$ (see Table 1), resulting in an average daily cost per placement of $\$ 88.92$, corresponding to about 0.71 hours (or 42 minutes) per day. However, as noted in Table 2, large variation in worker time per day exists by group, and hence the group average costs vary in a corresponding way, as shown in Figure 3.

\footnotetext{
${ }^{8}$ As the worker changed over during the study in the remaining placement, this case was excluded from the worker experience analysis.
} 


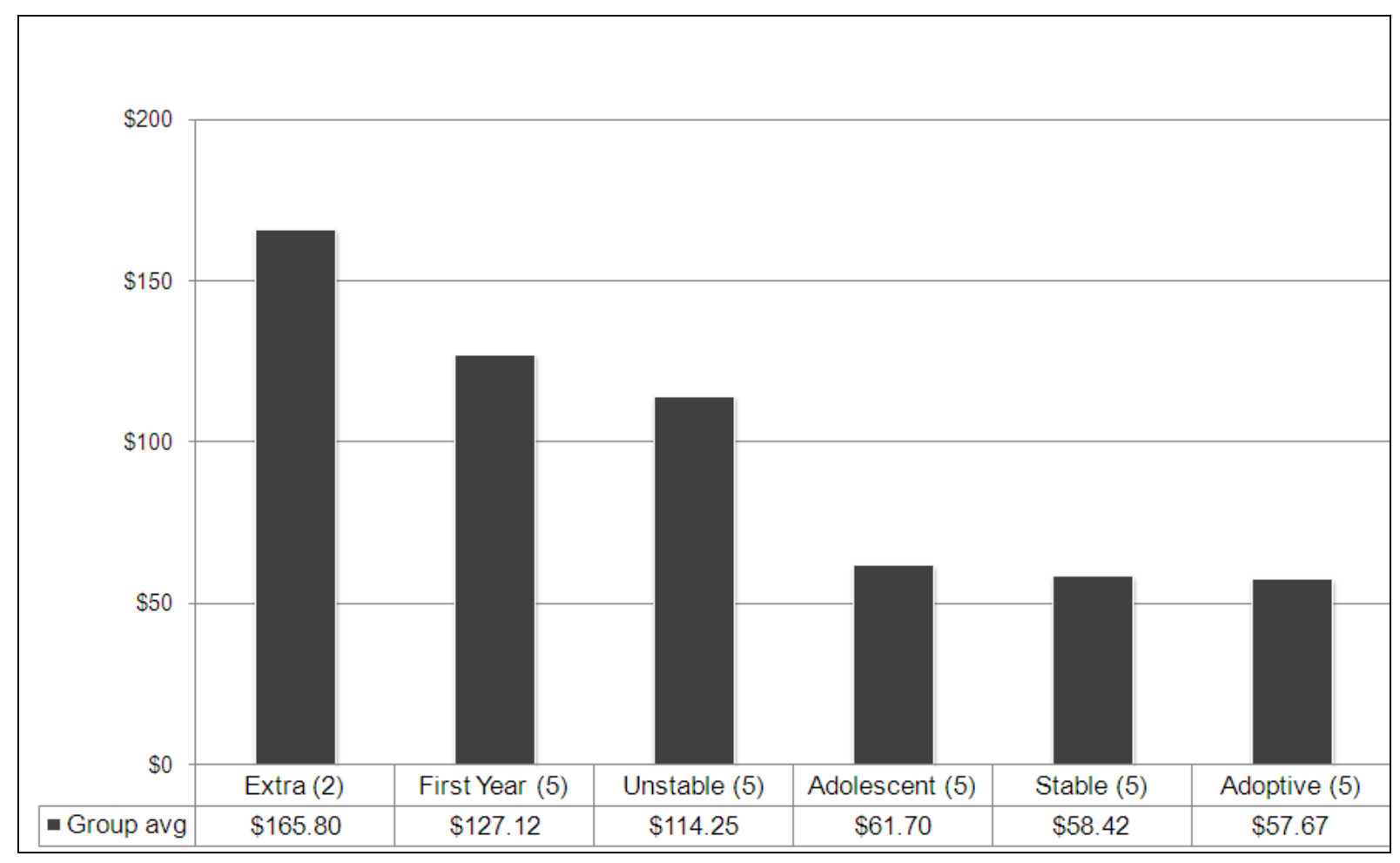

Figure 3: Average cost per day, by group. Here the worker average hours per day for the cases within each group are multiplied by the representative cost of $\$ 125.60$ per hour. The number of cases in each group is given in parentheses following the group label in the table.

Similarly, we find a large difference in worker average cost for long term placements associated with a plan for adoption as compared with those without adoption, as shown in Figure 4. This figure may reflect the fact that placements need to be stable before an adoption care plan is put into action. However, it also shows that the commonly held view that adoption work remains time intensive, compared with other long term placements in this program, is not supported by the study data. 


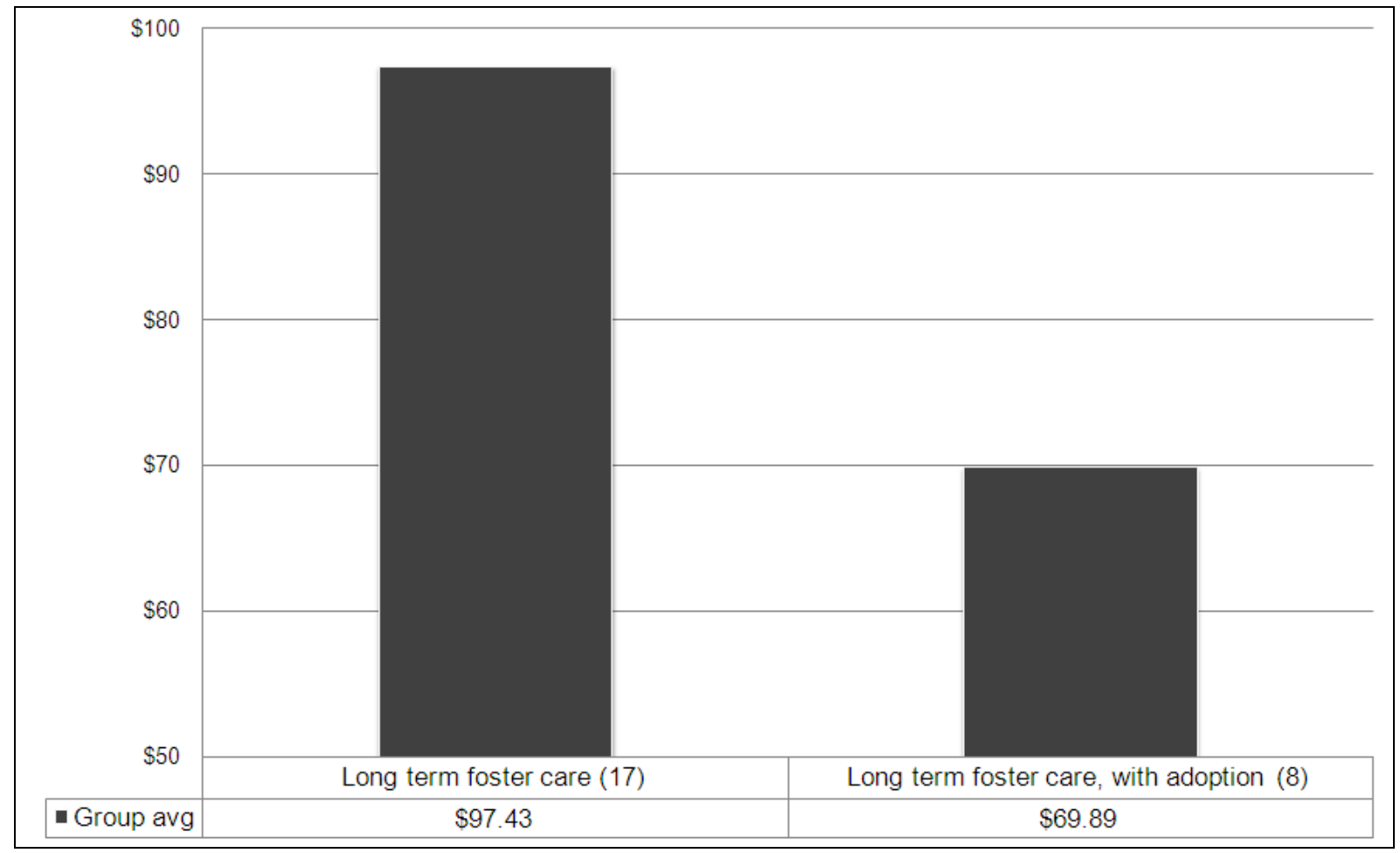

Figure 4: Average cost per day, by care plan. Here the worker average hours per day for the cases within each category are multiplied by the representative cost of $\$ 125.60$ per hour. The number of cases in each category is given in parentheses following the category label in the table.

Figure 5 shows the average cost per day, per worker, relative to the number of years the child or young person has spent in any care program. This figure demonstrates that the worker average cost per day is relatively highest in relation to placements in the first two years in any care program, and tends to decline the longer the child is in care. 


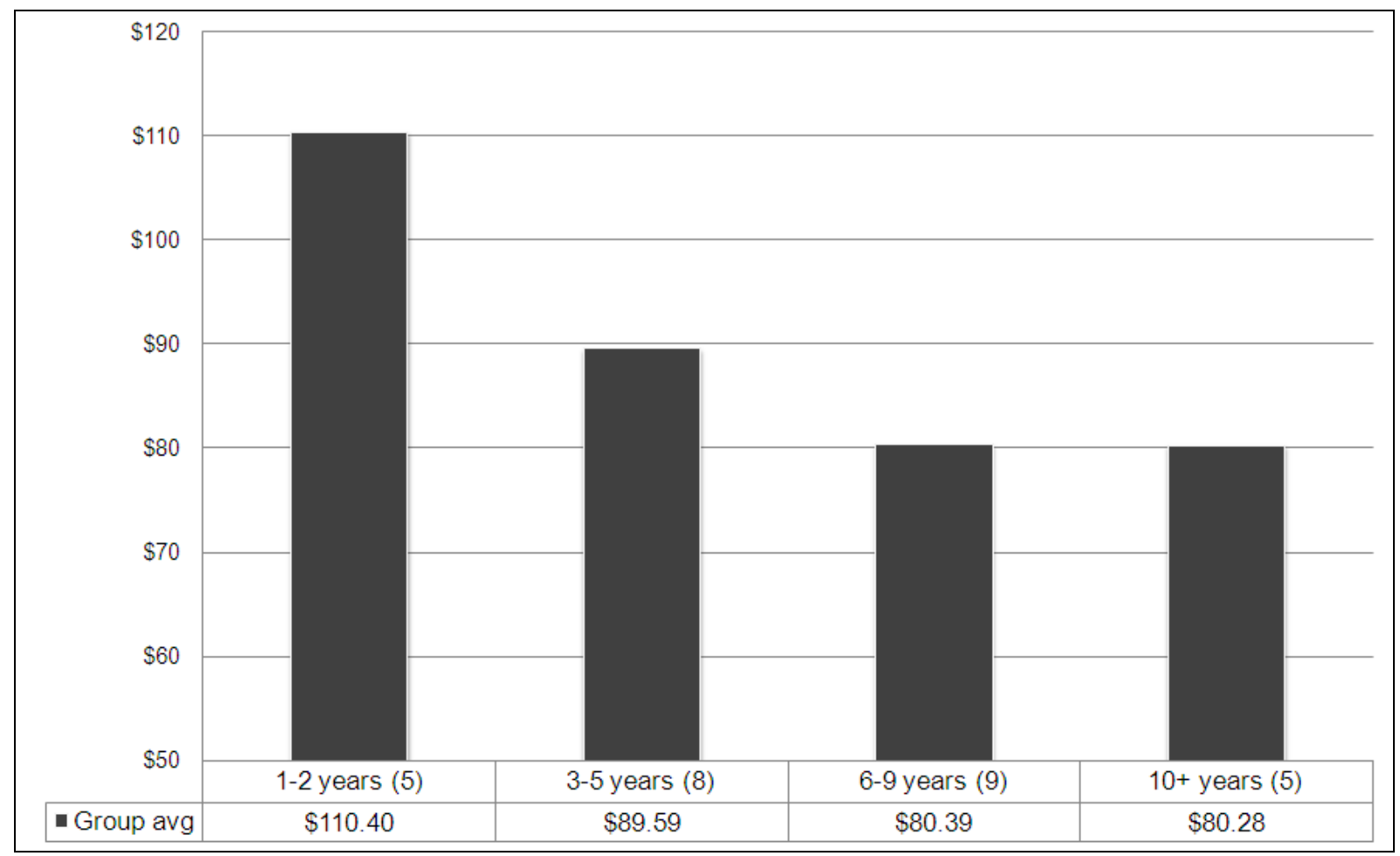

Figure 5: Average cost per day, by time in any care program. Here the worker average hours per day for the cases within each care duration group are multiplied by the representative cost of $\$ 125.60$ per hour. The number of cases in each care duration category is given in parentheses following the category label in the table.

\section{Discussion}

The Cost of Support research has confirmed much of the 'practice wisdom' of adoption and foster care workers. Using a robust ‘bottom up’ methodology, the research has produced accurate time and cost findings for placement support in an organisation with a known level of stability in care. We have demonstrated that the cost of this kind of work is considerable, especially given the fact that work to recruit carers was not included in the study. In addition, we have demonstrated that both workers (and carers) are able to maintain an intensive 'diary' methodology over an extended period of time, contributing significantly to accuracy in costing. 
This builds on the work of Ward \& Holmes (2008), who used a focus group methodology to arrive at estimates of time and costs; and subsequently Holmes et al. (2008), who used a more limited 'event record’ methodology.

There are two major issues which have become increasingly apparent to the researchers and the Barnardos staff over the course of the study. Firstly, variability is a key issue, which is apparent throughout the sample - i.e. it is not restricted to placements requiring higher levels of support. The study has shown that placement agencies need to allow for considerable variability in worker time:

- In terms of age, gender and previous time in care.

- During a child's placement journey - with little worker support needed at some times and significant amounts at other times;

Between children in a similar category - even in a group of children of similar age and placement background, some will need far greater support than others.

Secondly (and related to variability), although the required level of support can be anticipated to some degree (e.g. for first year placements), it is difficult to predict which children and placements will need 'spikes' of support, or when these will be needed, or what kind of support will be appropriate. Similarly, placement disruptions are hard to predict. Five children in this study were initially chosen because their workers considered that their placements were potentially unstable and yet all of these placements were intact at the end of the research. Two other children, whose placements were in difficulty, joined the study partway through the nine months and yet neither of these placements disrupted before the end of the study (although one of these disrupted some months later). 
Variability and unpredictability mean that placement agencies need to have enough staff hours and flexibility to be able to respond quickly to crises and requests for support.

The study showed that a significant amount of worker time is involved in supporting first year placements and unstable placements (inclusive of the initial 'Unstable Group’ and the 'Imminent Risk Group'). We could speculate that the intensive support provided in the first year, as well as to subsequently unstable placements, leads to a greater degree of stability than has been reported in other research.

The costing model, independently developed and based on both salary and non-salary factors, is one that could be adapted for other countries or agencies. Ultimately it may be possible to compare findings with other services with different program structures, costing formulae and stability rates.

\section{Conclusions}

This paper contributes to the debate on the factors leading to stability of a placement by detailing the level of worker support provided to individual placements within a program that has an established high rate of stability. By using a diary method over a relatively lengthy period of nine months to track the time and activity of workers of twenty-seven separate placements in the FAF program, detailed information regarding the level of support provided to different types of placements and the types of activities that are most important to maintaining those placements within the program were obtained. From this approach, a greater understanding is gained regarding the relative frequency of various worker activities, and the financial resources required to sustain a placement. 
The study found that workers spend the highest proportion of their time on contact issues with carers and potential adoptive parents, administration related to the child, interaction with children, and contact with carers and children together. Other time was spent on work with the birth family, organizing visits and work related to adoption. In addition, the characteristics of placements that are associated with higher than average support requirements are explored, providing insight into the factors that contribute to the variability in support needs found within the study. The research findings, along with the detailed description of the study program, methodology and the inclusion of the costing formula, will enable other programs to compare their practice, outcomes and costs.

\section{Role of the funding source}

This research was supported by The Ian Potter Foundation, 'The cost of support in long term foster care and adoption’ project grant. The Ian Potter Foundation did not play any role in the study design; nor in the processes of collection, analysis or interpretation of data; nor in the writing of any reports or articles; nor in the decisions related to submission of papers for publication in any journal.

\section{References}

Allphin, S., Simmons, B. \& Barth, R.P (2001). Adoption of foster children: How much does it cost public agencies? Children and Youth Services Review, 23(11), 865-891.

Barber, J. \& Delfabbro, P. (2003). Placement stability and psychosocial well being of children in foster care. Research on Social Work Practice, 13(4) 415-431. 
Beecham, J. (2004). Unit Costing: Not Exactly Child's Play. The Department of Health, Dartington Social Research Unit and the Personal Social Services Research Unit at the University of Kent, UK.

Beecham, J. \& Sinclair, I. (2007). Costs and Outcomes in Children's Social Care. Jessica Kingsley, London.

Brown, J. D. \& Bednar, L. M. (2006). Foster parent perception of placement breakdown. Children and Youth Services Review, 28(12), 1497-1511.

Christiansen, Ø., Havik, T., \& Anderssen, N. (2010). Arranging stability for children in long term out of home care. Children and Youth Services Review, 32(7), 913-921.

Cheers, D. \& Morwitzer, J. (2008). Promoting resilience on outcomes. Promoting Resilience in Child Welfare. R. J. Flynn, P. M. Dudding \& J. G. Barber (Eds.) University of Ottawa Press, Ottawa, Canada

Conrath, D. W., Higgins, C. A. \& McClean, R. J. (1983). A comparison of the reliability of questionnaire versus diary data. Social Networks, 5 (3), 315-322.

Delfabbro, P., Jeffreys, H., Rogers, N., Wilson, R., \& Borgas, M. (2009). Certainty for Children in Care. Children with stable placment histories in South Australian out-of-home care. Research Bulletin, South Australian Government Department for Families and Communities.

DHS (Department of Human Services) (2003). Public Parenting: A Review of Home-based Care in Victoria. Melbourne, Department of Human Services.

Fernandez, E. (2006). Growing up in care: Resilience and care outcomes. Promoting Resilience in Child Welfare. R. J. Flynn, P. M. Dudding \& J. G. Barber (Eds.) University of Ottawa Press, Ottawa, Canada.

Fernandez, E. (2008). Unravelling Emotional, Behavioral and Educational Outcomes in a Longitudinal Study of Children in Foster-Care. British Journal of Social Work, 38(7), 1283-1301.

Fernandez, E. (2009). Children's wellbeing in care: Evidence from a longitudinal study of outcomes. Children and Youth Services Review, 31, 1092-1100. 
Gilbertson, R. L. \& Barber, J. G. (2004). The systemic abrogation of practice standards in foster care. Australian Social Work, 57(1), 31-45.

Holmes, L., Westlake, D. \& Ward, H. (2008). Calculating and Comparing the Costs of Multidimensional Treatment Foster Care, England (MTFCE): Report to the Department for Children, Schools and Families. Loughborough: Centre for Child and Family Research, Loughborough University.

Ingley, G. \& Earley, L. (2008). One in, one out? The delimma of having multiple children in foster placement. Adoption and Fostering Journal, 32(3), 73-85.

Jackson, S. \& Thomas, N. (1999). On the Move Again? What works in creating stability for Looked After Children. Barkingside, Barnardos United Kingdom.

James, S. (2010). Promoting placement stability by studing the dynamics and antecedents of placment instability. Child Welfare $360^{\circ}\left(C W 360^{\circ}\right)$, Spring, 12-13. Center for Advanced Studies in Child Welfare (CASCW), School of Social Work, College of Education and Human Development, University of Minnesota.

Jones, A. S. (2010). Promoting placement stability in foster care: A roadmap through the literature. Child Welfare $360^{\circ}\left(C W 360^{\circ}\right)$, Spring, 8-9. Center for Advanced Studies in Child Welfare (CASCW), School of Social Work, College of Education and Human Development, University of Minnesota.

Mathiesen, S. G., Jarmon, B. J. \& Clarke, L. (2001). Searching for family: Voices of Florida's foster children. Journal of Family Social Work, 6(1), 15-33.

O'Neill, C. (1997). Policy and practice implications of permanent placement disruption. Australian Social Work, 50(2), 41-47.

O'Neill, C., Tregeagle, S., Forbes, C., Cox, E. \& Humpheys, C. (2010). Research Report Summary: The cost of support for stable foster care and adoption placements. Developing Practice, No. 27, Summer, 28-37.

Oosterman, M., Schuengel, C., Slot, N. W., Bullens, R. A. R. \& Doreleijers, T. A. H. (2007). Disruptions in foster care: A review and meta-analysis. Child and Youth Services Review, 29(1), 53-76. 
Pecora, P. J. (2010). Why should child welfare focus on promoting placment stability? Child Welfare $360^{\circ}\left(C W 360^{\circ}\right)$, Spring, 4-5. Center for Advanced Studies in Child Welfare (CASCW), School of Social Work, College of Education and Human Development, University of Minnesota.

Rindfleish, N., Bean, G. \& Denby, R. (1998). Why foster parents continue and cease to foster. Journal of Sociology and Social Welfare, XXV (March).

SCRGSP (Steering Committee for the Review of Government Service Provision) (2010). Report on Government Services 2010, Productivity Commission, Canberra.

Selwyn, J., Frazer, L. \& Quinton, D. (2006). Paved with good intentions: The pathways to adoption and the cost of delay. British Journal of Social Work, 36(4), 561-576.

Selwyn, J. \& Sempik, J. (2010). Recruiting adoptive families: The costs of family finding and the failure of the agency fee. British Journal of Social Work. doi:10.1093/bjsw/bcq075.

Selwyn, J., Sturgess, W., Quinton D. \& Baxter, C. (2006). Costs and Outcomes of Non-infant Adoption. British Association of Adoption and Fostercare, London.

SNAICC (Secretariat of National Aboriginal and Islander Child Care) (2008). Service Development, Cultural Respect and Service Access Policy. SNAICC, Inc. policy paper, August. Retrieved from www.snaicc.asn.au.

Sudol, T. (2010). Placement stability and CFSR. Child Welfare $360^{\circ}\left(C W 360^{\circ}\right)$, Spring, 10. Center for Advanced Studies in Child Welfare (CASCW), School of Social Work, College of Education and Human Development, University of Minnesota.

UK (United Kingdom) Department of Health (1999). Adoption Now. R.A. Parker (Ed.) London, John Wiley \& Sons, Inc.

Unrau, Y. \& Day, A. (2010). The importance of understanding the placment move experience from the perspective of foster youth. Child Welfare $360^{\circ}\left(C W 360^{\circ}\right)$, Spring, 11 . Center for Advanced Studies in Child Welfare (CASCW), School of Social Work, College of Education and Human Development, University of Minnesota.

Ward, H. \& Holmes, L. (2008). Calculating the costs of local authoritity care for children with contrasting needs. Child and Family Social Work, 13(1), 80-90. 
Appendix: The cost of support in foster care and adoptive placements - caseworker weekly recording chart

Child: XY (code to be kept by agency). Week: Mon $1^{\text {st }}>$ Sun 7th

Please record in 15 minute blocks DAILY

\begin{tabular}{|c|c|c|c|c|c|c|c|}
\hline $\begin{array}{l}\text { Worker time (incl. face to face time, } \\
\text { phone calls and travel) spent with/on: }\end{array}$ & $\begin{array}{l}\text { Monday } \\
\text { 1st }\end{array}$ & $\begin{array}{l}\text { Tuesday } \\
\text { 2nd }\end{array}$ & $\begin{array}{l}\text { Wednesday } \\
\text { 3rd }\end{array}$ & $\begin{array}{l}\text { Thursday } \\
\text { 4th }\end{array}$ & Friday $5^{\text {th }}$ & $\begin{array}{c}\text { Weekend } \\
\text { Sat } 6^{\text {th }} / \text { Sun } 7 \text { th }\end{array}$ & Total \\
\hline \multicolumn{8}{|l|}{ Foster carers/adoptive parents only } \\
\hline \multicolumn{8}{|l|}{ Child/ren only } \\
\hline \multicolumn{8}{|l|}{ Carers/children together } \\
\hline \multicolumn{8}{|l|}{$\begin{array}{c}\text { Education issues - schools, tutoring, } \\
\text { etc }\end{array}$} \\
\hline \multicolumn{8}{|l|}{$\begin{array}{c}\text { Legal issues - specify e.g. } \\
\text { consultation with lawyers, Court, etc }\end{array}$} \\
\hline \multicolumn{8}{|l|}{ Adoption related work } \\
\hline \multicolumn{8}{|l|}{ Birth family } \\
\hline \multicolumn{8}{|l|}{$\begin{array}{c}\text { Access arrangements and supervision } \\
\text { - parents }\end{array}$} \\
\hline \multicolumn{8}{|l|}{$\begin{array}{c}\text { Access arrangements and supervision } \\
\text { - siblings }\end{array}$} \\
\hline \multicolumn{8}{|l|}{$\begin{array}{l}\text { Access arrangements/supervision - } \\
\text { other (e.g. extended family, previous } \\
\text { carers) }\end{array}$} \\
\hline \multicolumn{8}{|l|}{ Health issues } \\
\hline \multicolumn{8}{|l|}{ Counselling issues } \\
\hline \multicolumn{8}{|l|}{ Internal meetings } \\
\hline \multicolumn{8}{|l|}{$\begin{array}{c}\text { Meetings with other agencies - DOCS, } \\
\text { etc }\end{array}$} \\
\hline \multicolumn{8}{|l|}{ Supervision/consultation } \\
\hline $\begin{array}{c}\text { Administration - case notes, reports } \\
\text { etc }\end{array}$ & & & & & & & \\
\hline Other & & & & & & & \\
\hline
\end{tabular}

